\title{
La posibilidad de renunciar a la acción de nulidad del laudo arbitral en el ordenamiento jurídico ecuatoriano
}

\section{The possibility to waive the annulment of the arbitral award under the Ecuadorian legal system}

\section{Diego Mateo Guerra Romero *}

Recibido / Received: 07/05/2021

Aceptado / Accepted: 24/10/2021

DOI: $10.18272 /$ ulr.v8i2.2273

Citación:

Guerra Romero, D.M. «La posibilidad de renunciar a la acción de nulidad del laudo arbitral en el ordenamiento jurídico ecuatoriano». USFQ Law Review, Vol 8, no 2, octubre de 2021, pp. 77-104, doi: $10.18272 /$ ulr.v8i2.2273.

* Alumni de la Universidad San Francisco de Quito USFQ, casilla postal 17-1200-841, Quito 170901, Pichincha, Ecuador. Correo electrónico: die_gue12@hotmail.com ORCID iD: https://orcid.org/0000-0003-2670-7656 


\title{
RESUMEN
}

La acción de nulidad del laudo arbitral ha sido reconocida como el remedio procesal para la revisión de la validez del laudo bajo causales específicas determinadas en la ley. Sin embargo, esta revisión está prevista para ser ejecutada por órganos judiciales, lo que deviene en una inevitable interacción de la justicia ordinaria con el arbitraje. Esta inevitabilidad presenta una distinción, pues varias legislaciones extranjeras han previsto la posibilidad de excluir este control en la sede del arbitraje para extenderlo hacia la sede de ejecución.

Esto deviene en una discusión incierta sobre aquellos países que nada han establecido al respecto, como Ecuador, ya que la renuncia a esta acción podría estar prohibida por el ordenamiento, en la medida en que trastoque limitantes de orden público. El análisis ecuatoriano indica que la renuncia, dentro de este ordenamiento, es factible siempre y cuando se acoja a un estándar que -precisamente- garantice este control.

\section{Palabras clave}

Arbitraje; acción de nulidad; laudo arbitral; renuncia; orden público

\begin{abstract}
The annulment of the arbitral award has been recognized as the procedural remedy for the review of the validity of the award under specific grounds determined by law. However, this review is foreseen to be executed by judicial bodies, which results in an inevitable interaction of ordinary justice with arbitration. This inevitability presents a distinction, as several foreign legislations have stated the possibility of excluding this control from the seat of arbitration and extend it to the seat of enforcement.

This leads to an uncertain discussion in those countries that have not established anything in this regard, such as Ecuador, since the waiver of this action could be prohibited by the law to the extent that it violates the limits of public order. The Ecuadorian analysis indicates that the waiver, within this legal system, is feasible as long as it complies with a standard that, indeed, guarantees this control.
\end{abstract}

\section{KEYWORDS}

Arbitration; annulment; arbitral award; waiver; public order 


\section{INTRODUCCIÓN}

Aunque el arbitraje se base en la autonomía de la voluntad, dejando en libertad a las partes para excluir - por la expresión de su voluntad- sus controversias de la justicia ordinaria, esto no significa que su sujeción a arbitraje esté en completa independencia del poder judicial. Si bien los árbitros pueden decidir sobre el fondo del asunto, es común que las legislaciones nacionales establezcan la posibilidad de que el poder judicial controle el procedimiento arbitral y su producto -el laudo- mediante una acción o recurso de nulidad frente a este último.

La interacción que presentan el arbitraje y el poder judicial involucra entonces un nudo problemático que consiste en hallar un equilibrio que logre compatibilizar un grado razonable de autonomía del arbitraje con un grado igualmente adecuado de control judicial. ${ }^{1}$ Ambos factores son asumidos como criterios clave para fomentar el desarrollo eficiente de la institución arbitral.

Uno de los problemas que se ha derivado de esta interacción es el relacionado con la renuncia a la acción de nulidad. Esta acción se reconoce, en la mayoría de los ordenamientos jurídicos, como la única y exclusiva herramienta para la impugnación del laudo por lo que muchos teóricos consideran que la materia reviste alta importancia al tratarse de un tema de orden público, condicionando a dicha acción a la irrenunciabilidad. ${ }^{2}$

Este trabajo enfoca su análisis justamente en eso: la posibilidad que tienen las partes para renunciar a la acción de nulidad. Esto, especialmente, si se analiza en qué medida se trastocan mínimas inderogables de orden público cuando el objeto de protección, el control judicial de la nulidad en la sede, puede ser desplazado en una misma esencia garantista al juez del exequátur.

Por un lado, la discusión ha respaldado el espíritu de protección detrás de la irrenunciabilidad bajo la idea de resguardar disposiciones imperativas nacionales -en la medida en que se compatibilice el control a los árbitros en atención a la equivalencia que representa el laudo con la sentencia judicial-. Por otro lado, legislaciones como Suiza, Suecia, Bélgica, Francia, Panamá y Perú han previsto la posibilidad limitada de renunciar a este recurso.

Las mencionadas legislaciones han armonizado el control de la nulidad con el control sujeto al exequátur, por lo que es posible desplazar esta revisión del laudo en la sede del arbitraje hacia una revisión similar en la sede de reconocimiento y ejecución. ${ }^{3}$ Es importante mencionar que esta posibilidad se refiere

1 Roque J. Caivano, "La renuncia a los recursos", en Cuestiones claves del Arbitraje Internacional, coord. de E. Gaillard y D.P. Fernández (Bogotá: Editorial Universidad del Rosario, 2013), 133.

2 Roque J. Caivano, Arbitraje, (Buenos Aires: ed. Ad Hoc, 2000), 289.

3 Ver Jesús Remón Peńalver, "Sobre la anulación del laudo: el marco general y algunos problemas", InDret: Revista para el 
exclusivamente a casos de arbitraje internacional en el que existe un laudo que deba ser homologado y ejecutado, pues aquellos laudos locales o referidos a legislaciones que prevean la ejecución inmediata del mismo, no justificarían este desplazamiento.

La legislación ecuatoriana no se refiere expresamente a la posibilidad de las partes de renunciar a la acción de nulidad; sin embargo, el texto de la Ley de Arbitraje y Mediación (en adelante LAM) se inclina a favorecer el desarrollo del arbitraje y su eficacia. La renuncia a la acción de nulidad tiene como objetivo final favorecer también dichos parámetros, por lo que representa una clara muestra de la relevancia institucional que puede ofrecer esta discusión al arbitraje dentro de cada ordenamiento jurídico.

Desde esta visión es posible analizar si existen limitaciones al orden público que están siendo vulneradas a nivel del ordenamiento local, específicamente las garantías básicas de carácter procesal constitucionalmente instituídas en el artículo 76 de la Constitución de la República del Ecuador (en adelante CRE). ${ }^{4}$ Sobre esta base, este trabajo se pregunta lo siguiente: jes la renuncia a la acción de nulidad contraria a las garantías procesales constitucionalmente establecidas que se enmarcan en el orden público interno ecuatoriano?

Para responder esta pregunta, en este trabajo se recopilan las diferentes posiciones frente a la situación, una comparación de los diversos ordenamientos jurídicos a nivel internacional que discuten el tema y, finalmente, una aproximación a la perspectiva ecuatoriana para entender cuál es la mejor propuesta para implementar dentro de la legislación nacional.

La investigación parte de supuestos generales y una mera contextualización del problema jurídico para poder entender qué teorías y pronunciamientos existen detrás del tema explorado. Con base en estas premisas, se aterrizará el problema dentro del marco jurídico ecuatoriano para poder definir si efectivamente en Ecuador es posible esta renuncia o no.

\section{INSTRUMENTOS NORMATIVOS SOBRE LOS QUE SE FUNDA LA MATERIA}

El arbitraje se ha desarrollado como un reconocido método de resolución de controversias ancladas a una diversidad de fuentes de derecho. Esto cataloga a la materia como una herramienta diversificada dentro del ámbito nacional e internacional. En el escenario nacional, se reconoce a la validez del arbitraje en

Análisis del Derecho 3 (2007), 1-19; Fabio Núńez del Prado Chaves, "El recurso de anulación de laudo y el derecho a patalear", Themis Revista de Derecho 71 (2017), 13-30; Alberto Zuleta Londońo, "La renuncia al recurso de anulación contra el laudo en el Arbitraje Comercial", Revista Ecuatoriana de Arbitraje 3 (2011), 245-261.

4 Artículo 76, Constitución de la República del Ecuador, R.O. 449, 20 de octubre de 2008. 
el artículo 190 de la CRE ${ }^{5}$ y el artículo 1 en la LAM. ${ }^{6}$ Debido a la gran convergencia de sistemas normativos inmersos en este método, se pueden identificar una serie de instrumentos que dan las pautas para delimitar el ámbito de aplicación de la materia.

Entre ellos se encuentran convenciones de carácter internacional, soft law y específicamente, la legislación propia de cada Estado referente al arbitraje. Dos instrumentos específicos que contienen disposiciones respecto de la acción de nulidad del laudo arbitral son la Ley Modelo de Arbitraje Internacional de la Comisión de las Naciones Unidas para el Derecho Mercantil Internacional (en adelante Ley Modelo CNUDMI) ${ }^{7}$ y la Convención sobre el Reconocimiento y Ejecución de las Sentencias Arbitrales Extranjeras de 1958 (en adelante $\mathrm{CNY}){ }^{8}$

El espectro jurídico desarrollado por la Ley Modelo CNUDMI pretende ser una guía replicable para todas las legislaciones arbitrales a nivel mundial. ${ }^{9}$ Sus causales de anulación del laudo son una recopilación que puede ser fácilmente adoptada por cualquier ley de arbitraje. En concreto, las disposiciones de esta ley, perteneciente al bloque de soft law internacional, se han implementado de manera parcial en Ecuador dentro de la LAM. ${ }^{10}$

Por su parte, la CNY tiene como principal objetivo el facilitar el reconocimiento y ejecución de los laudos en los países que la han ratificado. A su vez, entabla dentro de su texto una serie de referencias con respecto a la nulidad del laudo, siempre dentro del escenario de la ejecución de este. Específicamente, en lo que compete a este estudio, la Convención empata las causales de denegación para el reconocimiento de un laudo ${ }^{11}$ en las causales perseguidas por la Ley Modelo CNUDMI para que se pueda interponer una acción de nulidad.

\section{Posturas teóricas frente a la renuncia a la aCCión de NULIDAD}

Desde el enfoque doctrinario y una limitada legislación en el derecho comparado, la posibilidad de renuncia a la acción de nulidad del laudo arbitral se ha

5 Artículo 190, Constitución de la República del Ecuador, 2008.

6 Artículo 1, Ley de Arbitraje y Mediación, R.O. 417, 14 de diciembre de 2006, reformada por última vez R.O. Suplemento 309 de 21 de agosto de 2018.

7 Ley Modelo de la Comisión de las Naciones Unidas para el Derecho Mercantil Internacional sobre Arbitraje Comercial Internacional [Ley Modelo CNUDMI], 1985, enmendada en 2006.

8 Convención sobre el reconocimiento y ejecución de las sentencias arbitrales extranjeras [Convención de Nueva York], Nueva York, 10 de junio de 1958, ratificada por el Ecuador el 17 de diciembre de 1958.

9 Ver Nota explicativa de la secretaría de la CNUDMI, Ley Modelo CNUDMI, párr. 2.

10 Ver Eduardo Carmigniani, Carla Cepeda, "Implementación (parcial) en Ecuador de principios de la Ley Modelo CNUDMI sobre arbitraje comercial. Retrospectiva histórica y necesidades", Revista Ecuatoriana de Arbitraje 8 (2016), 349-373.

11 Ver Artículo V, Convención de Nueva York. 
centrado en dos posiciones contrapuestas. La primera postura, evidentemente, admite esta posibilidad, aunque generalmente condicionada. Una segunda línea de pensamiento argumenta que no es posible renunciar a esta acción y su carácter de irrenunciabilidad tiene su asentamiento en la idea de que es una herramienta otorgada por la ley de cada Estado y, por lo tanto, el impedimento recae sobre las leyes imperativas y el orden público interno de cada país.

La primera arista, que apoya el enfoque del presente estudio, reconoce una diferenciación entre aquellos laudos que han sido expedidos internamente, de aquellos de carácter internacional, ejecutables en otro Estado diferente al de la sede. En estos últimos, a primera vista, no se evidencia contravención alguna a garantías básicas del ordenamiento, toda vez que existe finalmente un control judicial del laudo en la instancia de reconocimiento y ejecución bajo el amparo del artículo V de la CNY. ${ }^{12}$ Esta teoría ha sido recogida por países como Suiza, Suecia, Túnez, Bélgica, Francia y Perú.

La segunda, mantiene la idea de que la acción de nulidad se reconoce como un remedio procesal impugnatorio que el legislador ha creado para el efecto y, por ende, se ha incorporado al bloque de garantías mínimas de orden público que resguardan la materia. Aquí, la necesidad de control judicial que tienen los laudos es inevitable y no puede ser desconocida por las partes ya que los motivos de anulación se concentran en irregularidades vinculadas con el debido proceso y el derecho a la defensa. ${ }^{13}$

\section{Situación ACTUAL de la DOCTRINA SObRE LA RENUNCIA A LA ACCIÓN DE NULIDAD}

Roque Caivano ha reconocido grosso modo que el laudo siempre será susceptible de ser objetado bajo la figura de la nulidad y con respecto de aquellas causales que cada legislación prevea. ${ }^{14}$ Recalca que el objeto de esta instancia impugnatoria es controlar las decisiones arbitrales en protección de aquellos recaudos que las legislaciones han catalogado como indispensables y contenidas en normas de orden público, por lo que se convierte en una revisión judicial irrenunciable. ${ }^{15}$

No obstante, en un análisis más profundo, Caivano también establece que -si bien esta impugnación se encuentra instituida en el orden público- la idea solo tiene sustento cuando se habla de arbitrajes domésticos o, incluso, aquellos internacionales cuyo laudo se ejecuta en el mismo Estado sede. Esto

12 Ver Caivano, "La renuncia a los recursos", 133-165; Remón, "Sobre la anulación del laudo", 1-19; Núnez, "El recurso de anulación de laudo", 13-30.

13 Remón, "Sobre la anulación del laudo", 13-14.

14 Caivano, Arbitraje, 288.

15 Ibid., 289. 
debido a que el fundamento que hace imperativa la existencia de control judicial sobre el laudo es que esta revisión es la única vía para impugnarlo. ${ }^{16}$ Esta discusión, sin embargo, carece de sentido cuando el laudo va a ejecutarse en otro Estado, pues dicho control se traslada al juez del lugar de ejecución dentro de la misma lógica de análisis de la nulidad. ${ }^{17}$

El pensamiento de Caivano, que permite la renuncia diferenciando entre laudos completamente internos ${ }^{18}$ e internacionales, tiene su antecedente en la línea presentada por los mayores teóricos del arbitraje. Merino Merchán y Chillón Medina, por ejemplo, indican que efectivamente la posibilidad de excluir esta modalidad de control por autonomía de la voluntad, consiste en un elemento diferenciador de los ordenamientos jurídicos con respecto al arbitraje internacional. Para ellos, resulta objeto de realce la posibilidad de contrarrestar el carácter de inatacable del laudo internacional dictado en el territorio de la sede, siempre que se salvaguarde el control mediante exequátur en otro país. ${ }^{19}$

Jesús Remón Peñalver ha establecido que el límite a la posibilidad de renunciar a la acción de nulidad se encuentra en las leyes imperativas y el orden público. Para él, los motivos de anulación se concentran en amparar el derecho a la defensa, dado que buscan la reparación de irregularidades especialmente graves. ${ }^{20}$ Sin embargo, la filosofía que patrocina la idea de permitir una renuncia anticipada a la impugnación por nulidad implica el contraste mismo del rol judicial dentro del arbitraje asociado a un correcto entendimiento del principio de la mínima intervención judicial. ${ }^{21}$

Similar criterio ha seguido Fabio Núnez del Prado, cuando afirma que esta renuncia sí es posible en ciertas situaciones pues el control judicial al que se refiere la materia, constata solamente un imperativo constitucional de que se controle el poder jurisdiccional que se ha otorgado a los árbitros con sus decisiones. ${ }^{22}$

Aclara que la acción de nulidad, como tal, no traspasa estas mínimas garantías imperativas en cada Estado. Incluso asevera, como los anteriores autores, que en la medida en que exista otro mecanismo -como el exequátur- que asegure

16 Ver Caivano, "La renuncia a los recursos", 133-165.

$17 \mathrm{Al}$ respecto, Gaillard y Savage seńalan: "[...] las bases sobre las que un laudo puede ser apartado [...] son generalmente asentadas sobre la filosofía que se encuentra en las bases para denegar el reconocimiento o ejecución encontradas en las Convenciones Internacionales relevantes". Emmanuel Gaillard, John Savage (ed), Fouchard, Gaillard, Goldman on International Commercial Arbitration (La Haya: Kluwer Law International, 1999), 966 (traducción no oficial).

18 Cabe aclarar que, al referirse a laudos internos, también deben tomarse en cuenta aquellos laudos domésticos en los que su ejecución, independientemente de que sea un arbitraje internacional, se pretende en el mismo territorio de la sede donde ha sido expedido.

19 José Fernando Merino Merchán, José María Chillón Medina, Tratado de Derecho Arbitral (Madrid: Editorial Civitas, 2006), 1765.

20 Remón, "Sobre la anulación del laudo", 13.

21 Ibid., 15

22 Núñez, "El recurso de anulación de laudo", 23. 
el mismo fin de control del laudo, entonces puede prescindirse sin mayor problema del mecanismo de anulación. ${ }^{23}$ Indica, por ende, que la renuncia aportaría una mayor eficacia al arbitraje siempre y cuando sea condicionada a que el modelo persiga el control en la instancia de ejecución del laudo. ${ }^{24}$

\section{LA ACCIÓN DE NULIDAD DEL LAUDO ARBITRAL}

La difusa percepción de la noción del laudo arbitral ha sido superada e internalizada como un concepto clave dentro del mundo del Derecho. Gaillard y Savage han delimitado el término como "una decisión final de los árbitros sobre todos los aspectos de la controversia que se les somete [...] que los lleve a poner fin al procedimiento". ${ }^{25}$ Se trata del producto de la actuación de los árbitros que denota el ejercicio de la jurisdicción que se les ha otorgado y reviste las características de una sentencia. ${ }^{26}$

Bajo esta similitud encontrada con la sentencia judicial se empieza a percibir en dónde se encuentra el contraste que denota la problemática estudiada en el presente trabajo. Mientras la sentencia judicial se ha sistematizado con revisiones ulteriores, el laudo arbitral, en cambio, se denota como un pronunciamiento de única instancia, que en la mayoría de los países será objeto de revisión en cuanto a "[...] ciertos recaudos y con relación a causales específicas". ${ }^{27}$ Esto es a lo que, precisamente, alude la figura de la acción de nulidad.

\subsection{DisTINCIÓN ENTRE ACCIÓN Y RECURSO}

Las diferentes aproximaciones que ha tenido la renuncia a la acción de nulidad se han planteado a partir de los diversos sistemas normativos que las exploran. Es por esta razón que resulta necesario aclarar que la mayoría de las legislaciones a nivel internacional, en conjunto con la doctrina sobre el tema, se refieren a la renuncia a la nulidad del laudo arbitral desde la perspectiva de un recurso. No obstante, un sector minoritario -pero igualmente válido y al que pertenece la legislación ecuatoriana- es aquel que denomina a esta herramienta como acción de nulidad por tramitarse como una acción autónoma conocida por la Función Judicial en un proceso diferente al arbitraje. ${ }^{28}$

$28 \mathrm{Al}$ respecto, el profesor Véscovi ha señalado que: "el objeto de la acción de nulidad es conseguir la nulidad de la resolución mediante un juicio distinto mientras que los recursos se tramitan dentro del proceso principal” Enrique Véscovi, Teoría general del proceso (Bogotá: Ed. Temis, 1999), 270-275. 
La acción de nulidad no es un recurso "sino una acción rescisoria, cuyo ejercicio da lugar a un proceso declarativo especial en el que se pretende [...] que el Tribunal se pronuncie acerca de la validez o no del laudo". ${ }^{29}$ Fuera de cualquier otro contraste, objeto de otro estudio, hay que denotar que ambas palabras se utilizan indistintamente en el presente trabajo dada la diversidad de la terminología jurídica a nivel internacional, a la que se hará referencia constantemente.

\section{LA RENUNCIA A LA ACCIÓN DE NULIDAD}

\subsection{El MARCO DE REPLICABILIDAD APORTADO POR LA LEY Modelo CNUDMI y SU ARMONÍA CON la CONVENCIÓN DE NUEVA YorK}

Una primera aproximación a la posibilidad de renuncia a la acción de nulidad del laudo arbitral es la derivada del análisis efectuado a las causales de anulación previstas en la Ley Modelo CNUDMI. Se trata de causales que no pretenden revisar el fondo de la controversia: su propósito último es revisar que "[...] el laudo se haya dictado de la manera escogida por las partes [...] respetando las normas a las cuales estaba sometido en materia de arbitrabilidad y orden público internacional". ${ }^{30}$

Lo propuesto por la Ley Modelo CNUDMI coincide con un deseo de dar pautas replicables a los diferentes regímenes de anulación del laudo para lograr la convergencia mundial de la materia. La relevancia de esta Ley resalta en la medida en que propone un solo tipo de recurso a un órgano judicial como medio para conseguir la impugnación de un laudo y, a su vez, dispone una lista taxativa de causales ${ }^{31}$ que, si se las contrasta con aquellas para la denegación de reconocimiento y ejecución de la CNY, coinciden esencialmente con las previstas en este último instrumento. ${ }^{32}$

La CNY, por su parte, respeta los procesos domésticos de cada país, toda vez que reconoce que cualquier sede puede tener procesos internos de control judicial que conduzcan a la anulación del laudo. ${ }^{33}$ Por eso establece condiciones especiales para la ejecución del laudo cuando aún no se ha resuelto la nulidad en la sede. ${ }^{34}$ De aquí la importancia de observar la armonía con la que funcionan ambos instrumentos.

\footnotetext{
Remón, “Sobre la anulación del laudo", 8.

Zuleta, "La renuncia al recurso de anulación contra el laudo", 249.

Ver, Artículo 34.2, Ley Modelo CNUDMI.

Remón, "Sobre la anulación del laudo", 4.

Zuleta, "La renuncia al recurso de anulación contra el laudo", 250.

Ver, Artículo VI, Convención de Nueva York.
} 
Lo expuesto en líneas anteriores podría representar un ideal proteccionista por parte de ambas normas, que, en virtud de la armonía de sus disposiciones correspondientes a la nulidad, demuestran que la ejecución respeta los mecanismos de control de la sede en el extranjero. ${ }^{35}$ Es decir, desde esta perspectiva sería factible asegurar que el control de la nulidad excede el puro interés de las partes, lo que vuelve inadmisible la renuncia a dicho control.

Sin embargo, como indica el profesor Remón, "la jurisdicción ${ }^{36}$ concentra su papel de control en los posibles vicios in procedendo y la garantía del orden público constituye un mero límite negativo [...]". ${ }^{37}$ Se refiere a que el tema del control, si bien resulta imprescindible, garantiza solo una revisión procedimental, no de fondo.

Esta revisión compatibiliza la eficacia del arbitraje con las garantías del debido proceso. No obstante, esta misma lógica deja ver que el proteccionismo que garantizan las normas y -en virtud, de nuevo, de la afinidad entre estas- el control al que refieren puede ser desplazado bajo la única condición de que se termine cumpliendo; es decir que en la medida en que se garantice la existencia de un control a vicios procedimentales del laudo. El análisis requiere, evidentemente, mayor profundidad. Empero, el marco impuesto por la Ley Modelo CNUDMI y la CNY da seńales de que el proceso de reconocimiento y ejecución también es una garantía de la vigilancia al debido proceso sobre el laudo.

\subsection{EL MODELO GENERAL SUIZO Y LOS CONTRASTES EN LA LEGISLACIÓN COMPARADA}

Como se ha mencionado previamente, algunas legislaciones prevén la posibilidad expresa de renunciar a la acción/recurso de nulidad dentro de sus leyes correspondientes. ${ }^{38}$ Dentro de las mismas, el modelo suizo es el que aporta mayor relevancia ya que permite la posibilidad de prescindir del recurso de anulación y reconoce la validez de una renuncia parcial, que permite escoger las causales particulares a ser relegadas. ${ }^{39}$ Lo anterior solo aplica si las partes

35 Zuleta, "La renuncia al recurso de anulación contra el laudo", 251.

36 Esta mención a la jurisdicción hace referencia a la facultad jurisdiccional que se le ha otorgado al juez ordinario para revisar la impugnación al laudo.

37 Remón, "Sobre la anulación del laudo", 4.

38 Ver Artículo 192, Ley Federal Suiza sobre Derecho Internacional Privado, [LDIP], 18 de diciembre 1987; Artículo 1717(4), Código Judicial belga, 27 de marzo de 1985, modificatoria de 1998; Sección 51, Ley Sueca de Arbitraje, 1 de abril de 1999; Artículo 1522, Código de Procedimientos Civiles francés, modificatoria de 2011; Decreto No. 2011-48 [que modifica la Ley de Arbitraje francesa], 13 de enero de 2011; Artículo 36, Decreto Ley No. 5, Presidencia de la República [por el cual se establece el régimen general de arbitraje de la conciliación y de la mediación panameńo], Registro Oficial de 8 de julio de 1999.; Artículo 63, Decreto Legislativo No. 1.071 [que reforma la Ley de Arbitraje peruana], 01 de septiembre de 2008 .

39 Domitille Baizeau, Franz Stirnimann, "Renuncia al derecho de impugnar un laudo. Estudio práctico sobre la experiencia suiza”, Lima Arbitration: Revista del Círculo Peruano de Arbitraje 4 (2010-2011), 151-168. 
no tienen relación con Suiza y cuando han celebrado un acuerdo expreso para el efecto. ${ }^{40}$

Este modelo -acertado por cierto en cuanto a los beneficios que realmente trae al arbitraje y que serán explorados en los próximos epígrafes de este trabajo- ha sido replicado por legislaciones como la peruana. Pese a que esta ley propone parámetros de renuncia muy claros, aún se reserva un mecanismo de revisión judicial a la luz del reconocimiento y ejecución del laudo.

[...] Así, un laudo ejecutado fuera de Suiza en un Estado miembro de la Convención de Nueva York [...] puede ser impugnado bajo cualquier causal contemplada en el Artículo V de la CNY. Por otro lado, una parte que pretende ejecutar en Suiza un laudo emitido en el extranjero [...] podrá invocar la CNY.41

No obstante, el problema que se trae a colación con estas disposiciones, compartidas generalmente por las demás legislaciones mencionadas, es el derivado de un laudo nacional suizo al que le aplicaría la Ley Federal Suiza sobre Derecho Internacional Privado (en adelante LDIP) ${ }^{42}$ y no la CNY, pues se tomaría como directamente ejecutable al no pretender reconocerse en territorio extranjero. Lo que adecuadamente hace Suiza, es que:

[...] [C]uando las partes hayan celebrado un acuerdo de renuncia válido, y hayan renunciado así a cualquier posible revisión del laudo en un proceso de nulidad, tendrán derecho a disputar la ejecución al amparo de la CNY, como si el laudo emitido en Suiza fuera un laudo extranjero. ${ }^{43}$

Entonces la legislación helvética, a pesar de imponer una ausencia de relación con Suiza para permitir la renuncia al recurso de nulidad y requerir un pacto por escrito, también denota dentro de sus disposiciones la imperiosa necesidad de que la renuncia a la impugnación de laudos domésticos asimile al laudo como uno extranjero para efectos de la aplicación de la CNY. Así, el laudo se homologa bajo las causales dispuestas por la CNY, lo que garantiza que el control judicial sobre el laudo arbitral sea previsto en todos los casos posibles. ${ }^{44}$ De aquí que Suiza, efectivamente, garantiza las mínimas inderogables alegadas a favor de la irrenunciabilidad del recurso.

No obstante, existen países que se muestran aún más permisivos frente a esta renuncia. Recogiendo lo establecido por Suiza, los reconocidos tratadistas Redfern y Hunter se refieren a Francia y establecen que "[...] Under the 2011

40 Ver Artículo 192(1), LDIP

41 Baizeau, Stirnimann, "Renuncia al derecho de impugnar un laudo", 163-164.

42 Ver Artículo 192(2), LDIP.

43 Baizeau, Stirnimann, "Renuncia al derecho de impugnar un laudo", 164.

44 A propósito, Fabio Núnéz cuenta la anécdota belga cuando se eliminó el recurso de anulación. Señala que Bélgica tuvo que reconocer su ingenuidad al pretender eliminar una barrera post-laudo esencial para garantizar la seguridad de las partes. En lugar de convertirse en una sede atractiva, atrajo el resultado contrario. Ver, Núńez, "El recurso de anulación de laudo", $14-15$. 
French Arbitration Law, this right to waive the right to challenge extents to any party". ${ }^{45}$ En definitiva, Francia permite la renuncia sin condicionamientos de nacionalidad, domicilio/residencia o establecimiento comercial.

Es necesario considerar que el derecho permitido para renunciar a cualquier impugnación por nulidad, en Francia, no tiene nada que ver con una ausencia de control judicial absoluta pues la orden de ejecución -l'ordonnace d'exequatur-, sigue siendo irrenunciable. ${ }^{46}$ Esto deviene en una misma lógica suiza en tanto se permite desplazar el control judicial al laudo, desde la instancia de nulidad en la sede, a la instancia de ejecución.

Evidentemente, el problema aterriza sobre una base de imperatividad de normas básicas y necesarias para el buen funcionamiento de cada ordenamiento. Si la renuncia se entiende desde la limitación conceptual que deriva desde esta sola lógica, bien podría establecerse como referente de plena eficacia arbitral al modelo panameño. ${ }^{47}$ A pesar de que en Panamá se había seguido la tendencia impuesta por países como Bélgica y Suiza, canceló rotundamente la posibilidad de renuncia a partir de un pronunciamiento constitucional por contravenir -en una presunción muy amplia- a la garantía del debido proceso. ${ }^{48}$

En definitiva, Panamá solamente logró integrar una idea de protección absoluta al impedir la renuncia anticipada y en abstracto ${ }^{49}$ a una falencia procedimental que las partes aún desconocen debido a que solo puede ser visibilizada después de expedido el laudo. Para esta legislación, básicamente, resulta un impedimento exante a que las partes sean libres de renunciar a la acción de nulidad cuando aún desconocen el alcance de su renuncia. ${ }^{50}$

Lo expuesto por estas legislaciones revela la necesidad de concretar, de manera precisa, cuándo la renuncia llega a violar preceptos de carácter supra legal. Los preceptos de orden público validan la dominancia que ha tenido la irrenunciabilidad de la acción o, en la mayoría de casos, ni siquiera una mención en lo absoluto. Sin embargo, las garantías universalmente asumidas sobre el debido proceso ${ }^{51}$ deben definir a qué punto específico sobre el debido proceso protegen. Si la protección recae solamente en beneficio de sus sujetos -los beneficiarios del sistema legal- el objeto de la norma y su espíritu imperativo podrán dispersarse lejos de dicha protección.

45 Nigel Blackaby, Constantine Partasides, Alan Redfern, Martin Hunter, Redfern and Hunter on International Arbitration, Sexta Edición (Oxford: Oxford University Press, 2015), 578.

46 Zuleta, "La renuncia al recurso de anulación contra el laudo", 254-255.

47 Ver Art. 36, Decreto Ley No. 5, 1999.

48 Ver Expediente No. 109-05, Corte Suprema de Justicia, Sala Cuarta de Negocios Generales, 7 de octubre 2005.

49 "[...] una norma con jerarquía legal que permita a las partes renunciar anticipadamente y en abstracto al ejercicio de un medio de impugnación es contraria a la garantía fundamental del debido proceso". Ibid.

50 Zuleta, "La renuncia al recurso de anulación contra el laudo", 255-256.

51 "El derecho al debido proceso busca confirmar la legalidad y correcta aplicación de las leyes dentro de un marco de respeto mínimo a la dignidad humana dentro de cualquier tipo de proceso [...]" Víctor Manuel Rodríguez Rescia, "El debido proceso legal y la Convención Americana sobre Derechos Humanos", Revista de la Facultad de Ciencias Jurídicas y Politicas de la Universidad Central de Venezuela 110 (1998), 328. 


\subsection{POSIBLES POSICIONES}

Lo antedicho anuncia ya un breve matiz de las posibilidades respecto al tema. Por un lado, indudablemente, un primer argumento defendería la procedencia de la renuncia tajantemente; sin criterios adicionales a tomar en cuenta. Otro, más adecuado, permitiría la renuncia al recurso de anulación en la medida en que desplace el control judicial hacia el exequátur. Finalmente, la tercera respuesta diría que no es posible renunciar a la acción de nulidad en ningún caso ya que se enmarca en una plena indisponibilidad para las partes; criterio que este ensayo desecha de entrada por las razones ya explicadas.

Con respecto a la primera posibilidad, esta sería apoyada por el razonamiento explorado a partir de la corriente contractualista que aboga por el resguardo de la esencia que da origen al arbitraje. Rivarola ilustra un paradigma acertado refiriéndose a la extrapolación de las garantías procesales -judiciales- dentro del arbitraje. Explica que estas tendrían válida vigencia y aplicación inmediata al arbitraje mientras no se opongan a su naturaleza pues sería un despropósito que garantías como la doble instancia, sean adheridas al arbitraje en analogía judicial, cuando es una concepción universal que las leyes o reglamentos arbitrales del mundo reconocen mayoritariamente la inapelabilidad de los laudos. $^{52}$

Es necesario complementar lo anterior con una clara exposición de a qué se refiere esta no oposición a la naturaleza del arbitraje. Bullard dedica un análisis completo a la defensa de la naturaleza contractual del arbitraje y apoya -salvo extrañas excepciones- que la misma es de origen contractual, característica deslindada del convenio arbitral. ${ }^{53}$ Explica, en referencia al recurso de anulación que:

[1]o que corresponde es sustituir una visión publicista del recurso de anulación que lo visualiza como un mecanismo de garantía de Derecho procesal, es decir, de naturaleza pública- por una visión privatista -que lo visualiza como una garantía de Derecho contractual, es decir, de naturaleza privada-. Ello debe conducir a un cambio de perspectiva con relación a lo que los jueces ordinarios hacen al conocer de un recurso, eliminando de su visión aspectos vinculados al Derecho procesal -como el de debido proceso- y enfocándose en figuras contractuales más acordes con su naturaleza $[\ldots] . .^{54}$

Esta posición es tomada con base en una serie de sustentos teóricos que tienen como misión principal defender el carácter contractual del arbitraje desde un

52 José Domingo Rivarola Reisz, Fabio Núnez Del Prado Chaves, "Nulla executio sine titulo: el escrutinio de los laudos en la práctica del arbitraje internacional como mecanismo para optimizar la ejecución de los laudos en el Perú”, Derecho PUCP 78 (2017), 76.

53 Alfredo Bullard G., “¿Qué fue primero: el huevo o la gallina? El carácter contractual del recurso de anulación”, Revista internacional de arbitraje (2013), 55-93.

54 Ibid., 82. 
análisis derivado de los límites impuestos por el convenio arbitral. Este trabajo, por otro lado, deriva sus hallazgos partiendo desde un momento posterior, el laudo y su respectiva impugnación.

Es por lo anterior que, si bien el criterio de Bullard resulta muy preciso, no puede revelarse compatible con el análisis desplegado en este estudio. Resulta inadecuado asumir que nada tienen que ver las garantías de orden público -desde una visión global del proceso arbitral- sobre una posible renuncia a la nulidad cuando, como se ha explicado ya previamente, la posibilidad de renunciar o no a la anulación del laudo se afinca necesariamente sobre el criterio de mínimas operativas para la correcta interacción arbitral-judicial, en un momento posterior al laudo. ${ }^{55}$

\section{EL LÍMITE DE LA RENUNCIA Y EL CASO ECUATORIANO}

\subsection{Ley de Arbitraje y Mediación ecuatoriana}

Esta norma toma como base la Ley Modelo CNUDMI y regula el proceso de nulidad que podrá solicitarse en contra de un laudo en el marco arbitral ecuatoriano. Dentro de este escenario, se sustenta en la Ley Modelo en tanto admite a la acción de nulidad ${ }^{56}$ como el único método de impugnación frente al laudo arbitral. ${ }^{57}$

A diferencia de los países estudiados, Ecuador en su referente normativo arbitral, la LAM, no regula de manera expresa la posibilidad o no de renunciar a la acción de nulidad. El artículo 31 de la LAM solo prevé las causales a partir de las cuales se puede interponer la misma. No obstante, en principio es preciso entender cómo se asimila esta herramienta dentro del ordenamiento ecuatoriano. La Corte Constitucional lo ha sintetizado al referir que:

[...] la acción de nulidad fue concebida como un medio de impugnación extraordinario por errores in procedendo en el arbitraje y vicios de extra petita en la decisión, relacionados al debido proceso arbitral y establecidos taxativamente en el artículo 31 de la Ley de Arbitraje y Mediación como causales de nulidad del laudo. ${ }^{58}$

55 Ver Caivano. Arbitraje, 94-96.

56 Ver Artículo 31, LAM.

57 Carmigniani, Cepeda, "Implementación en Ecuador de principios de la Ley Modelo CNUDMI", 370.

58 Sentencia No. 31-14-EP/19, Corte Constitucional del Ecuador, 19 de noviembre de 2019, párr. 41. 


\subsection{El MODELO ECUATORIANO}

Más allá del limitado marco que establece el mencionado artículo 31, resulta una tarea complicada el definir sobre qué parámetros aterriza la renuncia a la acción de nulidad en Ecuador. Sin embargo, lo aportado en líneas anteriores por otras legislaciones otorga una primera imagen. Panamá, por ejemplo, exhibe un claro limitante a la validez de la renuncia desde su jurisprudencia constitucional y alude básicamente al debido proceso. ${ }^{59}$

Como se observa en la jurisprudencia constitucional ecuatoriana, también se manifiesta que el trabajo de la acción de nulidad es dilucidar errores procedimentales que rodean el espectro del debido proceso. ${ }^{60}$

En España, Remón alude también a este limitante de orden público constitucional recogiendo criterios que ha emitido su jurisprudencia. Como el artículo 76 de la Constitución en Ecuador, en España el artículo 24 de su carta fundamental condensa los derechos fundamentales a los que la jurisprudencia española se refiere. $\mathrm{Al}$ respecto indica que:

[...] la jurisprudencia constitucional ${ }^{61}$ tiene declarado que [...] el derecho a la tutela deja en libertad al legislador para diseñar el sistema de recursos o acciones de impugnación que en cada caso considere más adecuado [...] una vez que un recurso o remedio procesal es creado por la ley se integra en el contenido del derecho a la tutela y se sitúa, por tanto, fuera de la capacidad de disposición de las partes [...] como elemento de orden público. ${ }^{62}$

De aquí se desprende la razón por la cual este estudio gira en torno a esclarecer los preceptos mínimos que gobiernan la materia y entablan la respuesta al por qué podría o no renunciarse a esta herramienta. Definitivamente, el debido proceso es el marco delimitante, no solo dentro de Ecuador. En este ordenamiento, la Carta Magna alude al debido proceso dentro de su artículo $76,{ }^{63}$ dentro del que se encuentran garantías básicas como el derecho a la defensa que, en términos generales, es lo que una corriente que se opone a la renuncia a la acción de nulidad pretende proteger.

59 Caivano señala que dicho tribunal consideró que la norma que aceptaba la renuncia vulneraba el debido proceso, ya que el derecho a la defensa involucra la posibilidad de las partes para utilizar todos los recursos que la ley les otorga para impugnar una decisión adversa, por lo que no pueden renunciar de manera anticipada a ellos; la renuncia impediría ejercer el único remedio posible contra irregularidades constituidas como causales en la ley. Ver, Caivano, "La renuncia a los recursos", 147.

60 Ver Sentencia No. 323-13-EP/19, Corte Constitucional del Ecuador, 19 de noviembre de 2019 (explicando cómo la acción de nulidad, como mecanismo de impugnación, está diseñada para examinar vicios in procedendo en tutela del debido proceso y el derecho a la defensa incurridos en la justicia arbitral).

61 Ver Sentencia 69/2005, Tribunal Constitucional, Sala Primera, 4 de abril de 2005, FJ 2; Sentencia 218/2006, Tribunal Constitucional, Sala Segunda, 3 de julio de 2006, FJ 3 (con relación a los remedios procesales que forman parte del contenido del derecho a la tutela).

62 Remón, "Sobre la anulación del laudo", 13.

63 Ver Artículo 76, Constitución de la República del Ecuador, 2008. 
Sin tener una referencia legal expresa sobre el tema, es necesario encontrar cuál es el justificativo real que podría evitar que en Ecuador se reconozca la validez de una renuncia a la nulidad. El marco general indica que el modelo a seguir es el suizo que prevé la mayor cantidad de escenarios posibles y es muy claro en cuanto a sus requisitos. No obstante, no se trata de una mera replica normativa, supuesto tras el cual el presente estudio no tendría ningún sentido; sino más bien adecuar aquellos principios generales que guían la interacción judicial-arbitral que garantizan la eficacia del arbitraje.

Un posible camino para analizar se presenta desde el estudio español que, al igual que Ecuador, no tenía referencia expresa a lo que la doctrina denomina como pacto de exclusión. ${ }^{64}$ Se alude a que, frente a la falta de previsión legal expresa, la solución se encuentra en los principios generales del ordenamiento interno, particularmente aquellos que limiten la autonomía de la voluntad. ${ }^{65}$

El artículo 11 del Código Civil ecuatoriano prescribe: "Podrán renunciarse los derechos conferidos por las leyes, con tal que sólo miren al interés individual del renunciante, y que no esté prohibida su renuncia" ${ }^{66}$ Esta única referencia dentro del ordenamiento legal ecuatoriano no parece suficiente para asimilar que la renuncia a la acción de nulidad, a pesar de su nombre, sea en realidad una efectiva renuncia de derechos conferidos por ley.

Evidentemente los principios que guían la materia arbitral hacen de esta renuncia una que mira al interés de las partes, pero la discusión vuelve -de nuevo- a si contraviene garantías absolutas que confieren una indisponibilidad para acordar por ser parte del orden público. Sin estar regulado, no puede existir tampoco pronunciamiento sobre una tajante posición de prohibición.

De cualquier modo, lo que realmente busca la renuncia es fijar el contenido de la relación jurídica de las partes, de una manera diferente a lo previsto por la ley ${ }^{67}$-en este caso la LAM-. De esta forma, en la medida en que exista control en el exequátur, el debido proceso no se cruza con la renuncia a la nulidad. Esto conlleva implícita la lógica de que importa la esencia de protección del control judicial sobre el laudo, independientemente de en dónde se desarrolle el mismo. ${ }^{68}$

64 Ver Remón, "Sobre la anulación del laudo", 12.

65 Ibid.

66 Artículo 11, Código Civil [CC], R.O. Suplemento 46, 24 de junio de 2005, reformado por última vez R.O Suplemento 96 de 08 de julio de 2019.

67 Remón, "Sobre la anulación del laudo", 12.

68 Caivano explica: "[...] se pretende con ello que exista una instancia judicial de control inderogable, de modo de satisfacer la exigencia de garantizar el acceso a la justicia [...] como principio de rango constitucional”. Roque J. Caivano, "El Rol del poder judicial en el Arbitraje Comercial Internacional”, en Arbitraje Comercial Internacional - Reconocimiento y Ejecución de Sentencias y Laudos Arbitrales Extranjeros, ed. del Departamento de Derecho Internacional de la Secretaría de Asuntos Jurídicos de la Organización de los Estados Americanos (OEA: Documentos Oficiales, 2015), 97-127. 
Se trata en realidad de un pacto conjunto entre las partes que deniega el control judicial al laudo dentro de la sede del arbitraje, cuando lo que prevé la ley es precisamente una revisión judicial de la decisión arbitral por causales taxativas únicamente previstas para la anulación en la sede. Esta decisión solamente encontraría una prohibición imperativa dentro del ordenamiento si es que la materia estuviese catalogada plenamente como de orden público, es decir, que interese infaliblemente "las nociones más básicas de moralidad y de justicia de un sistema jurídico". ${ }^{69}$

Lo que debe precisarse aquí es que si esto encajara como un supuesto de exclusión de la acción sobre una barrera infranqueable, como lo son las leyes imperativas y el orden público de cada ordenamiento, ${ }^{70}$ entonces se estaría frente a una renuncia inválida. Esto toda vez que el orden público, en su arista más importante -la constitucional-integra una serie de garantías que diseñan un sistema de protección a la luz del debido proceso y que se traducen en limitantes de la autonomía de la voluntad de las partes. ${ }^{71}$

Por el contrario, las legislaciones expuestas no han explorado el tema desde la absoluta certeza de su improcedencia. Más bien lo asimilan como una renuncia válida, intuyendo que no se trata de una barrera infranqueable. Además, algunas como la Suiza, han logrado un resultado merecedor de un análisis más profundo.

Es menester desmembrar aún más la propuesta y seguir explorando su posibilidad en el ordenamiento ecuatoriano. A pesar de ser necesarias más precisiones específicas al ordenamiento en referencia, la lógica que antecede permite ver, desde ya, una respuesta positiva frente a la posibilidad de renuncia en Ecuador.

Es claro que el escenario de la renuncia solo tiene fundamento en la medida en que evite un doble control judicial que interrumpa la eficacia del arbitraje y su independencia ${ }^{72}$ garantizada por el principio de mínima intervención judicial. Pero también es necesario entender que no se pueden condicionar las difusas limitaciones solo desde la respuesta a cuándo se producirían o no los efectos deseados de una apropiada regulación. Los principios, garantías y límites públicos de cada ordenamiento pueden separarse de la universalidad general que gobierna la materia.

En cualquier caso, un estudio apropiado dentro del escenario ecuatoriano supone el llegar a definir cuál efectivamente es el rol que tiene la jurisdicción

69 Ver Caso Parsons y Whittemore Overseas Co. c. Societe Generale de L'Industrie du Papier (RAKTA), Corte de Apelaciones de Estados Unidos para el Segundo Circuito. Sentencia de 24 de diciembre de 1974.

70 Remón, "Sobre la anulación del laudo", 13.

71 Ibid.

72 Núńez, "El recurso de anulación de laudo", 23. 
ordinaria dentro del arbitraje. ${ }^{73}$ La referencia a la imperatividad de supuestos esenciales no resulta suficiente. En la medida en que se expliquen conceptos como la mínima intervención judicial dentro del arbitraje, que ha sido mencionado, pero no abordado en mayor amplitud, la respuesta dejará ver que el Poder Judicial no posee sino un rol asistencial dentro de un control tanto prescindible como inevitable. $^{74}$

\section{Principios de la materia arbitral en juego}

\subsection{Mínima inTERVENCiÓn JUdicial}

La naturaleza jurisdiccional del arbitraje es ya indiscutible. ${ }^{75}$ No obstante, el arbitraje debe coexistir debidamente con la justicia ordinaria, "[...] los árbitros deberán comprender las limitaciones que les impone su origen convencional, la falta de imperium y el orden público" ${ }^{76} \mathrm{El}$ control que se reserva el Estado para sus jueces con respecto del arbitraje se circunscribe a ciertos aspectos fundamentales, lo que evita que este control se torne en otra instancia dentro del arbitraje. ${ }^{77}$ "Las atribuciones judiciales de control sobre el arbitraje -en su justa medida- son legítimas, justificadas y hasta convenientes". ${ }^{78}$

Se ha precisado, a partir de varias visiones doctrinarias, que el control judicial es, finalmente, inevitable y propicio mientras no exceda el propósito de rodear tanto al arbitraje como a la función de asistencia judicial del Estado de mayor seguridad, evitando posibles abusos por parte de los árbitros. Por supuesto, esta idea impone una fina línea delimitante de actuación de los jueces con respecto a la debida independencia de la institución arbitral. Esto es conocido como el eje de equilibrio que permite la correcta interacción entre ambas instituciones -arbitral y judicial-. La jurisprudencia española argumenta:

Es consustancial al arbitraje, por lo tanto, la mínima intervención de los órganos jurisdiccionales por virtud y a favor de la autonomía de la voluntad de las partes, intervención mínima que, tratándose de actuaciones de control, se resume en el de la legalidad del acuerdo de arbitraje, de la arbitrabilidad -entendida en términos de disponibilidad [...]- de la materia sobre la que ha versado, y de la regularidad del procedimiento de arbitraje. ${ }^{79}$

Por su parte, en Ecuador, la Corte Constitucional ha dejado muy clara la importancia que reviste este principio para la imperiosa necesidad de respetar la

73 Ver Caivano, "La renuncia a los recursos", 133-143.

74 Remón, "Sobre la anulación del laudo”, 15.

75 Caivano, "La renuncia a los recursos", 133.

76 Caivano, Arbitraje, 35.

77 Caivano, "La renuncia a los recursos", 143.

78 Ibid.

79 ATS 403/2006, Tribunal Supremo, Sala de lo Civil, 21 de febrero de 2006, FJ 1. 
autonomía que la misma Constitución impone al reconocer al arbitraje como un sistema alternativo de resolución de $\operatorname{conflictos}^{80}$ con normas y procedimiento propios.

La Corte comunica que las causales de nulidad previstas por el artículo 31 de la LAM son taxativas, impidiendo así pretender interponer una acción de nulidad fuera de las razones recogidas por la ley ${ }^{81}$ Lo anterior se deriva de la base del principio de la intervención judicial mínima sobre el cual la Corte establece que es - precisamente- el limitante a la interferencia injustificada de la justicia ordinaria sobre el arbitraje; también, la efectividad del arbitraje depende del respeto y la independencia que le otorgue la justicia ordinaria pues un control indiscriminado, violaría el carácter que la Constitución le confiere y anularía la voluntad de las partes. ${ }^{82}$

\subsection{EL ORDEN PÚBLICO}

La delimitación del espectro de análisis que se requiere para abordar de manera profunda la definición de la procedencia de la renuncia en Ecuador, deja ver que no solo se debe atender a la inevitable cooperación judicial, en su rol asistencial, con el arbitraje; también es necesario entender la interacción de sus ejes ideológicos. Tanto el contractualismo, que deriva en la conveniente independencia judicial de la que goza el arbitraje como método alternativo de resolución de conflictos, y el limitante filosófico de la renuncia, que deriva básicamente en una concepción procesalista del orden público constitucional; permiten observar la delgada línea a dilucidar.

Es necesario aclarar que el objeto del orden público sobre el cual se trabaja en el presente análisis se circunscribe, en Ecuador, dentro de las garantías del debido proceso ofrecidas por el artículo 76 de la Constitución -específicamente el numeral 7 respecto al derecho a la defensa- es decir, un orden público que se recoge constitucionalmente, pero en su matiz procesal.

Este concepto permite que aquellos principios básicos sobre los cuales el legislador ecuatoriano articula la correcta protección procesal, se identifiquen como el espíritu a resguardar por parte de los jueces con respecto a la revisión de la anulación del laudo. No pueden convertirse en una puerta falsa para que los jueces ordinarios tengan carta abierta para quebrantar la independencia arbitral y revisar la decisión de fondo del arbitraje. ${ }^{83}$

80 Ver Artículo 190, Constitución de la República del Ecuador.

81 Ver Sentencia No. 323-13-EP/19.

82 Ibid., párr. 33-37.

83 Remón. "Sobre la anulación del laudo", 15. 
De aquí que el límite de la materia se ratifique en el efectivo balance de la autonomía arbitral con el imperativo control judicial sobre errores procedimentales del laudo. Paralelamente, la falta de regulación sobre el tema en la legislación ecuatoriana inhibe analizar, de manera más precisa, dónde realmente puede trastocar el efecto negativo de la renuncia a la acción de nulidad en un eventual agravio al orden público. En consecuencia, se puede advertir que, al menos, es evidente que se debe proteger un orden público de carácter procesal y respecto de las garantías establecidas en la Constitución de la República sobre el debido proceso y el derecho a la defensa.

En todo caso, resulta atractivo analizar si el modelo suizo y sus requisitos, repetidamente apoyados durante este análisis, satisfacen las necesidades de control judicial aplicables para Ecuador.

\section{El Desplazamiento del CONTROL JUDiCial DE LA SEDE HACIA \\ EL EXEQUÁTUR}

Los autores recogidos en este trabajo tienen diferentes visiones y, en mayor o menor medida, ahondan sobre qué condiciones han de observarse para ubicar el adecuado límite a la renuncia. Su concepción recoge como referente al modelo suizo, peruano, espańol, panameńo, entre otros. De cualquier modo, todos exploran una misma lógica: el control judicial necesario dentro de la acción de nulidad y cómo este no necesariamente debe ser ejercido dentro de la sede, es decir, por los jueces que conocen la anulación. En la medida en que este mismo control pueda ser desplazado, al menos en esencia, a los jueces de ejecución, la renuncia tendrá pleno sentido y justificante.

En este sentido, cabe aclarar que los laudos con componente internacional imponen la necesidad de que los mismos sean ejecutados en un lugar diferente a donde fueron expedidos y de aquí se derivan varias implicaciones. En la medida en que este tipo de laudos se impugnen sobre la base de las vías procesales del lugar donde fueron proferidos, indica que estos entonces se remitirán a las causales que la legislación de dicha sede indique. Pero también tendrán que remitirse a una nueva revisión en los tribunales del lugar donde se los pretende ejecutar. ${ }^{84}$

Aunque la base del control en ambas instancias se comparte con evidente conexión, pues buscan a fin de cuentas controlar la actividad jurisdiccional del árbitro, el problema que revelan es -precisamente- un innecesario doble control para un mismo objetivo. En consecuencia, es esta sola modificación a la percepción generalísima de irrenunciabilidad, la que permite plantear una nueva concepción del recurso de anulación en la que las partes están plena-

84 Caivano, "La renuncia a los recursos", 158. 
mente facultadas para desistir de él, en la medida en que tengan por seguro que el mismo control será ejercido por quien se encargue del pedido de reconocimiento de su laudo. ${ }^{85}$

Esta misma garantía de control es definida por la legislación suiza que -como se ha expresado anteriormente- prevé la posibilidad de que las partes elijan renunciar a la revisión en la sede, siempre y cuando se presente eventualmente una revisión, de todas maneras, en la ejecución.

\subsection{LA EFICACIA DEL MODELO SUIZO}

Como ya ha sido evaluado, el modelo impuesto por Suiza dentro de su LDIP configura una propicia escala de equilibrio entre el control judicial a la validez del laudo y la debida autonomía arbitral. Además, previene un presupuesto extra que no se contempla por otras legislaciones, el que el laudo, a pesar de ser internacional, deba ser ejecutado dentro del mismo país sede. No tendría ningún sentido la renuncia en este último caso, en vista de la inoperancia que representa al ser el laudo ejecutable de inmediato dentro de la misma sede que lo expidió ya que se prescindiría de la revisión en sede de ejecución. ${ }^{86}$

En este sentido, el modelo suizo ha advertido una adecuada solución que es, efectivamente, prever la factibilidad del caso al imponer dentro de su LDIP ${ }^{87}$ que, aquellos laudos que han sido proferidos para ejecutarse dentro de la misma sede, deban seguir necesariamente un proceso de homologación al asimilarse como laudos extranjeros, para efecto de su control. Por lo tanto, el procedimiento de revisión judicial será garantizado incluso, cuando el mismo sea, en principio, improcedente.

La filosofía que inspira esta ley es la de tratar a los laudos como extranjeros cuando las partes así lo quieran -al renunciar al recurso de nulidad- y, por ende, los laudos cuyo único vínculo con la sede suiza es que las partes la han determinado como sede del arbitraje, exigen que a pesar de haber sido excluido del control judicial de anulación, sea necesario de todas maneras un proceso de reconocimiento previo a la luz de la CNY. ${ }^{88}$

85 Ver Núnez, "El recurso de anulación de laudo", 23-24.

86 Este es precisamente el caso ecuatoriano desde la reforma al COGEP en 2018 que elimina el proceso de homologación de laudos por lo que pasan directamente a un proceso de ejecución. Disposición Derogatoria Segunda, Ley Orgánica para el Fomento Productivo, Atracción de Inversiones, Generación de Empleo, y Estabilidad y Equilibrio Fiscal [Ley para el Fomento Productivo], R.O. Suplemento 309 de 21 de agosto de 2018.

87 Ver Artículo 192, LDIP.

88 Zuleta, "La renuncia al recurso de anulación contra el laudo", 253. 


\subsection{Presupuestos Para El CORReCto FunCIONAMIENTO Del MODELO SUIZO}

La LDIP, en su artículo 192, dispone que solo se aplicarán sus disposiciones sobre la renuncia anticipada a ejercer el recurso de nulidad en tanto se cumplan las siguientes condiciones: 1.- que las partes no tengan vínculo territorial con Suiza; ${ }^{89}$ 2.- que también hayan expresado su voluntad mediante escrito posterior o en el mismo convenio arbitral; ${ }^{90}$ y 3.- finalmente les permite limitar la elección de causales que quieren excluir ${ }^{91}$ correspondientes al artículo 190 de la misma ley.

Adicionalmente, el artículo mencionado otorga facultad a los tribunales suizos para revisar, incluso, aquellos laudos que podrían ser reconocidos automáticamente por pretenderse su ejecución dentro del mismo territorio suizo. Básicamente, de existir una renuncia al recurso de nulidad válidamente establecida, cualquiera de las partes puede pretender el reconocimiento y ejecución del laudo en Suiza aplicando la CNY por analogía, como si fuese una ley nacional. ${ }^{92}$

El efecto directo del artículo 192 de la LDIP es que el laudo no puede ser impugnado ante la Corte Suprema Federal suiza respecto de todas o algunas de las causales establecidas en el artículo 190(2) de la LDIP que han sido excluidas. ${ }^{93}$

\section{LA IMPROCEDENCIA DE LA ACCIÓN EXTRAORDINARIA DE PROTECCIÓN PARA SUPLIR AL EXEQUÁTUR}

Queda claro que en una mayoría de legislaciones, la ecuatoriana incluida, la acción de nulidad se toma como el único remedio a violaciones procedimentales. Sin embargo, se han trabajado nuevas posibilidades a partir de acciones-recursos dentro del ámbito constitucional. España, por ejemplo, ha determinado como única salvedad contra la decisión que pone término al juicio de anulación, la vía del amparo constitucional.

A partir de su negativa frente a la procedencia directa del recurso de amparo para impugnar el laudo arbitral, el Tribunal Constitucional de España ha determinado que las garantías procesales constitucionalmente recogidas,

89 Se refiere a que ninguna de las partes tenga su domicilio, residencia habitual o un establecimiento comercial [...] - entendido como 'cualquier establecimiento que, en dependencia de una sociedad principal [...], realice una actividad similar [...] gozando de cierta autonomía' Gini c. Tissage de toiles de Langenthal S.A., Corte Suprema Federal, 7 de marzo de 1977- en Suiza. Baizeau y Stirnimann. "Renuncia al derecho de impugnar un laudo", 153.

90 Ver requisitos establecidos por la Decisión 4A_53/2017, Tribunal Federal Suizo, 17 de octubre de 2017.

91 "[...] La posibilidad de excluir una o más causales de nulidad [...] solo se aplica si se cumplen dos condiciones: (A) cuando las partes no tienen relación con Suiza y (B) cuando han celebrado un acuerdo de exclusión específico para dicho efecto". Baizeau y Stirnimann. "Renuncia al derecho de impugnar un laudo", 153.

92 Ibid., 164.

93 Ibid., 163. 
tampoco pueden trasladarse con el mismo rango de derecho fundamental al procedimiento arbitral. ${ }^{94}$

Ecuador, por su parte, se ha asentado sobre una contraposición de criterios que terminan alterando el control al que está sometido el laudo arbitral. Primero, la Corte Constitucional expone un criterio en la sentencia No. 302-15-SEPCC en el que, virtualmente, amplía el espectro de las causales de anulación frente al laudo arbitral incluyendo a la falta de competencia y motivación como causales válidas a pesar de no ser recogidas por el artículo 31 de la LAM. ${ }^{95}$ Sin embargo, en un segundo momento, la actual Corte Constitucional se aparta de dicho pronunciamiento al establecer que este anterior criterio:

[...] atenta contra la taxatividad que tienen las causales de la acción de nulidad y que constituyen un efecto del principio de intervención judicial mínima que precisamente limita la interferencia injustificada de la justicia ordinaria en el arbitraje. ${ }^{96}$

El primer pronunciamiento de la Corte Constitucional abrió una puerta muy debatible sobre la necesidad de agotar la acción de nulidad en casos que, inclusive, no se enmarcan en las posibilidades estrictamente señaladas por el artículo 31 de la LAM; ${ }^{97}$ "[...] se convirtió a la acción de nulidad en una vía adecuada y eficaz para solventar cualquier vulneración a derechos constitucionales o al debido proceso durante el arbitraje", ${ }^{98}$ cuando esto es facultad de la acción extraordinaria de protección (en adelante AEP).

La nueva línea jurisprudencial rescata la posibilidad de remitirse directamente a la AEP para atacar vulneraciones que no encuentren sustento en la acción de nulidad y su lista recogida taxativamente. ${ }^{99}$ Con respecto a las vulneraciones que se enmarquen en las causales del artículo 31 de la LAM, la Corte establece que solo podrá proceder la AEP de manera residual, tras haber sido agotada la vía judicial para la nulidad.

Lo anterior demuestra que en Ecuador la AEP es una factible posibilidad que amplía las vías de impugnación que se tienen frente al laudo arbitral. Esto bien podría significar que entonces Ecuador garantiza, a fin de cuentas, un control

94 Cabe recalcar que, mientras los requisitos del derecho fundamental a la tutela judicial efectiva se reservan a la jurisdicción ordinaria, frente al arbitraje "[...] sólo proyecta sus garantías con el carácter de derechos fundamentales a aquellas fases del procedimiento arbitral y a aquellas actuaciones para las cuales la Ley prevé la intervención jurisdiccional de los órganos judiciales del Estado, entre las más relevantes, [...] el recurso o acción de anulación [...]” Sentencia 9/2005, Tribunal Constitucional, Sala Primera, 17 de enero de 2005, FJ 2.

95 Ver Sentencia No. 302-15-SEP- CC, Corte Constitucional del Ecuador, 16 de septiembre de 2015.

96 Sentencia No. 323-13-EP/19, párr. 32.

97 "Para activar la acción extraordinaria de protección contra un laudo arbitral, como una garantía constitucional de naturaleza jurisdiccional, se requería el agotamiento de la acción de nulidad únicamente por cinco causales taxativamente establecidas en la ley [...], las violaciones de derechos constitucionales no relacionadas a las causales de nulidad [...], podían ser directamente reclamadas ante la Corte Constitucional a través de la acción extraordinaria de protección." Sentencia No. 31-14-EP/19, párr. 52.

98 Ibid., párr. 53.

99 Ibid., párr. 54 
supletorio para aquellos casos no expresamente establecidos en el artículo 31 de la LAM. De esta manera no parece absurdo concluir que nada tiene que ver el análisis pretendido por el presente trabajo pues, en todo caso, la interacción del control judicial con el arbitraje no tendría cabida en este ordenamiento toda vez que se permite renunciar a la acción de nulidad en todos los casos ya que el control ordinario estará siempre presente en la vía constitucional.

No obstante, es menester entender de manera adecuada la línea de pensamiento de la Corte Constitucional que, en realidad, pretende aclarar la indebida interacción de la AEP con el control judicial al laudo y los indeseables efectos que esta confusión trae consigo. El tema, desde una limitada visión adecuada para analizarlo, desecha sin dudas que la AEP cambie el rumbo de análisis presentado. Incluso, se desecha la posibilidad de que la AEP supla la esencia del control que se pretende obtener al desplazar la revisión judicial, de la sede a la instancia de ejecución.

\section{DisCUSión FINAL}

En definitiva, es evidente que el punto focal de la discusión sobre la posibilidad o no de renunciar a la acción de nulidad como remedio procesal para los errores in procedendo incurridos en el laudo arbitral, se concentra en dilucidar la delgada línea entre dos aspectos. El primero, la renuncia a la acción de nulidad en términos generales. El segundo, un eventual control absolutamente garantista e indeseable sobre el orden público del laudo -que contiene garantías entendidas como acceso a la justicia, derecho a la defensa, debido proceso, entre otros- ${ }^{100}$

Por un lado, cuando se limita la discusión a la irrenunciabilidad, lo que sucede es que las partes a pesar de ser libres de determinar por su propia voluntad el someter a arbitraje las controversias que versen sobre sus derechos disponibles -excluyendo la decisión de fondo por los jueces ordinarios-, no podrían, en cambio, hacer valer su voluntad frente al control único y de carácter infranqueable que representa la revisión del laudo en la vía judicial de la sede tras una impugnación por nulidad.

La instancia de revisión por las causales de nulidad previstas por ley sería instituida entonces como improrrogable porque pretende analizar el laudo desde requisitos ordinariamente establecidos en normas adheridas al bloque de interés público. ${ }^{101}$ Resulta un criterio acertado pues no tendría sentido que la justicia ordinaria reciba la potestad de juzgar una nulidad sin al menos poder controlarla en concordancia con el debido proceso. El problema es que el res-

100 Julio C. Rivera, "La ejecución de laudos anulados y la CNY: tres perspectivas diferentes", Revista Derecho y Ciencias sociales, https://revistas.unlp.edu.ar/dcs/article/view/2361, 107.

101 Caivano, "La renuncia a los recursos", 153. 
paldar una irrenunciabilidad absoluta, deja a un lado ciertas particularidades que se derivan de la misma naturaleza arbitral.

A partir de esto, el presente trabajo ha distinguido aquellos presupuestos esenciales para el correcto entendimiento de la naturaleza que rige esta renuncia. La investigación denota que, de hecho, la renuncia es posible desde un marco de conveniencia que no mire esta figura como una imposibilidad tajante por ser contraria a un proteccionismo filosófico del orden público -en su arista procesal- debido a que es indispensable comprender, más bien, cómo debe funcionar una debida interacción entre la justicia ordinaria y el arbitraje. ${ }^{102}$

En consecuencia, el eje sobre el cual recae el análisis de contravención al orden público dentro de este trabajo se basa, en realidad, en un estándar de aplicación. El mismo impone la necesidad de mirar a la posibilidad de la renuncia respecto de la protección a mínimas garantías necesarias en todo proceso jurisdiccional, teniendo en cuenta que solo funcionaría una norma de este tipo en tanto prevea la posibilidad de realizar un control posterior al laudo, independientemente de en qué instancia se lo haga -a pesar de que, idealmente, la sede de ejecución prevea una revisión esencialmente similar a la de la sede de nulidad- ${ }^{103}$

Aunque sea indispensable revelar que la respuesta al problema jurídico, de manera general, se asienta sobre la estructuración de un modelo adecuado para su funcionamiento, el verdadero espíritu que impulsa la discusión del tema impide estancar el problema en una mera visión utilitaria.

Queda claro que es solamente en la medida en que se inhiba una debida protección procedimental al laudo, que se trastoca el límite de estos presupuestos inderogables de control judicial. Además, también es notable que este control puede ser desplazado mientras sea una manifestación expresa de la voluntad de las partes que no tengan un vínculo territorial con la sede. Lo segundo, parece indicar que el orden público se protege en la medida en que salvaguarde la protección de nacionales o residentes de la sede. Sin embargo, sería un despropósito no incentivar un mayor debate futuro sobre el tema que, indudablemente, genera nuevas preguntas académicas y prácticas.

Para efectos del análisis propuesto en este estudio, es primordial el enfoque de estos requisitos como pilares fundamentales para sostener un modelo que, bien entendido, demuestra no tener ninguna contraposición al orden público. Este precepto, esencialmente, recae sobre la imposición de un control inderogable al laudo arbitral. La renuncia debe aspirar a un desplazamiento del control judicial más que a una renuncia en estricto sentido. Esto es lo que, a 
fin de cuentas, las legislaciones extranjeras han previsto dentro de sus ordenamientos jurídicos.

No obstante, esta es la generalidad derivada de la renuncia como presupuesto viable dentro del arbitraje que, a su vez, se integra como una serie de distinciones de conveniencia más que verdaderamente de ineficiencia jurídica. En cualquier caso, impone un marco base para finalmente entablar una respuesta concreta a la pregunta de investigación y el objeto sobre el que recae: el ordenamiento jurídico ecuatoriano.

Partiendo de la inconveniencia que resulta el tener un doble control de una misma naturaleza -en la sede y en el exequátur-que reste eficacia al arbitraje, es necesario anunciar cuál es la ineficiencia que, en Ecuador, impediría esta renuncia.

En resumen, el desglose del orden público analizado para Ecuador en este trabajo señala que este, de manera general, se refiere a garantías procesales constitucionalmente establecidas, específicamente el artículo 76 de la CRE con respecto al debido proceso que, en una visión más estricta deviene en el derecho a la defensa. ${ }^{104}$ Un análisis final deriva en que la protección que impide la renuncia se basa en aquella garantía que provee a los usuarios del sistema judicial de una instancia de revisión ulterior que evite dejarlos en indefensión frente a la decisión sobre su proceso ${ }^{105}$-en este caso, la acción de nulidad para impugnar el laudo arbitral-.

Sin embargo, al no existir una norma expresa que delimite aún más el tema, parece adecuado identificar, en principio, el manto procesal que rodea a la renuncia a la acción de nulidad dentro de Ecuador, siempre encuadrando su discusión en garantías constitucionalmente recogidas.

En definitiva, la renuncia a la acción de nulidad, en lugar de verse como una contrapartida de esta secuencia de garantías constitucionales sobre las que trabaja la acción de nulidad, ratifica la necesidad de salvaguardar una revisión procedimental que proteja el orden público de los usuarios del sistema arbitral ecuatoriano.

\section{CONCLUSIONES Y RECOMENDACIONES}

Esta investigación ha permitido ahondar sobre los presupuestos esenciales a tener en cuenta para discutir sobre una posible renuncia a la acción de nuli-

104 Artículo 76(7), Constitución de la República del Ecuador, 2008.

105 Ver Sentencia No. 124-15-SEP-CC, Corte Constitucional del Ecuador, 22 de abril de 2015 (explicando cómo los mecanismos de impugnación son los instrumentos procesales - un fin que persigue también la acción de nulidad como remedio procesal al laudo provisto por la le - que permiten acceder a otras instancias de revisión con el propósito de garantizar el ejercicio pleno del derecho a la defensa, lo que constituye una garantía que configura su derecho constitucional al debido proceso). 
dad. Si bien el trabajo ha repasado doctrina, legislación y jurisprudencia que aboga por la indisponibilidad de la materia, definitivamente esta posibilidad es viable en la medida en que no contravenga el orden público y las mínimas inderogables del debido proceso y el derecho a la defensa.

Es indispensable entonces que esta posibilidad se envuelva dentro del manto de la correcta interacción judicial-arbitral, que tiene como último propósito resguardar este orden público asegurando una revisión procedimental sobre el laudo.

Por esta razón se recomienda configurar esta renuncia entendiendo la naturaleza que la impulsa, es decir, un correcto desplazamiento del control judicial indistintamente de la instancia en la que dicha legislación desee garantizarlo -judicial, constitucional o apropiadamente en armonía con la jurisdicción otorgada al arbitraje, en la sede de ejecución-. Así, el aceptar esta posibilidad, permite a las legislaciones arbitrales otorgar la eficacia que ha llevado a discutir la presente problemática.

Lo que en realidad se debe garantizar es entonces un estándar de control inevitable que proteja el laudo contra arbitrariedades in procedendo. Esto, siempre que se tenga en cuenta la verdadera balanza de la autonomía de la voluntad y el orden público, pues el segundo solo será protegido en tanto aborde la lógica de un esquema que garantice la posibilidad de revisar al laudo en un determinado momento.

Es necesario, también, diferenciar aquellos laudos domésticos -en donde la ejecución será automática por pretenderse dentro del mismo territorio en donde el laudo ha sido proferido- y aquellos laudos de arbitraje internacional en donde se persigue el reconocimiento y ejecución en un lugar distinto a la sede. Solo en el segundo caso tendrá pleno fundamento el que las partes renuncien a su acción-recurso de nulidad, toda vez que el laudo podrá tener, de todas maneras, una revisión al amparo del artículo V de la CNY en el exequátur, que es lo que al final del día se pretende resguardar.

Finalmente, con relación al ordenamiento jurídico ecuatoriano, el permitir la renuncia a la acción de nulidad arbitral no amenaza las garantías procesales mínimas establecidas por la legislación ecuatoriana para contar con un debido proceso, ya que en principio ni siquiera se trata de una estricta renuncia a derechos. Esto en realidad asegura la protección anhelada puesto que no se impone sobre aquello que resulta contrario al orden público -la falta de control judicial del laudo-. Solo lo desplaza.

La sugerencia que exhibe este trabajo para el correcto ejercicio de la renuncia a la impugnación del laudo por nulidad, corresponde a los requisitos expuestos por el modelo suizo y sus beneficios -expresados a lo largo del trabajo-. Estos 
son: que las partes no tengan relación con la sede y que hayan otorgado su voluntad expresa sobre este acuerdo.

De la misma manera, es necesario tener en cuenta la necesidad que representa la realidad de ordenamientos como el ecuatoriano, que imponen una ejecución automática de los laudos al eliminar el requisito de homologación. Para esto, también se sugiere adoptar el modelo suizo en tanto que obliga al laudo a ser asimilado como uno extranjero para efectos de su inevitable y necesario control. 